\title{
Effect of tractor wheel compaction on bulk density and infiltration rate of a loamy sand soil in Saudi Arabia
}

\author{
A. A. Al-Ghazal \\ Dept. of Agricultural Engineering, College of Agriculture and Food Sciences, King Faisal University \\ P.O. Box 762, Al-Hassa 31982, Kingdom of Saudi Arabia
}

\begin{abstract}
A field study evaluated the effect of tractor wheel compaction on soil bulk density and infiltration rate of a loamy-sand soil. The study was conducted at different two sites in the Kingdom of Saudi Arabia. Mean soil bulk density ranged between $1.55-1.79 \mathrm{~g} \mathrm{~cm}-3$ at the first site and $1.44-1.75 \mathrm{~g} \mathrm{~cm}-3$ at the second site under different tractor wheel compactions. Soil bulk density increased proportionally with repeated compaction and was related to soil moisture contents at the time of application of compaction force. However, mean cumulative water infiltration ranged between $1.53-5.79 \mathrm{~cm} \mathrm{hr}-1$ and the mean infiltration rate of soil between $1.32-5.70 \mathrm{~cm} \mathrm{hr}-1 \mathrm{in}$ different compaction treatments. Among the various compaction treatments, the "4-passes" treatment caused 69 $\%$ reduction in infiltration rate of soil. The highest compaction treatment (8-passes of tractor wheel) caused up to $77 \%$ reduction in infiltration rate of soil. Soil bulk density and infiltration rate of soil were highly correlated $(\mathrm{r}=0.887)$. The difference in soil bulk density and infiltration rate of soil was significant among all the compaction treatments when compared to the control treatment (zero-pass). The research findings showed an excellent potential for improving the physical properties of light textured soils to achieve higher irrigation efficiency if simply tractor (highly used conventional agricultural implement) coupled with other commonly adopted tillage practices are used for soil compaction.
\end{abstract}

Key words: Bulk density, tractor, compaction, infiltration, soil.

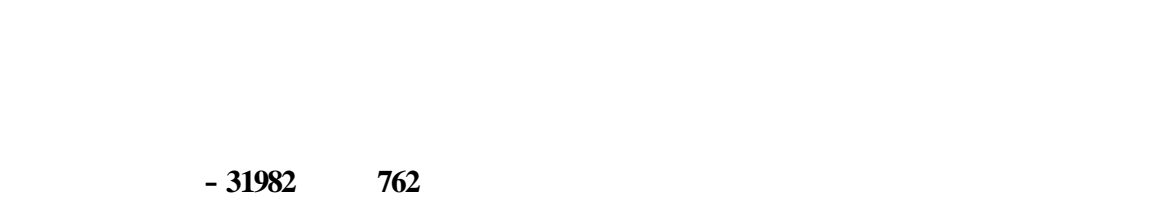

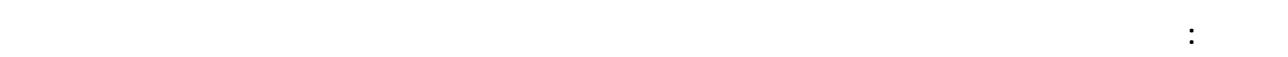

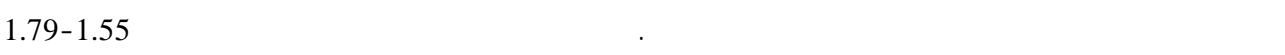

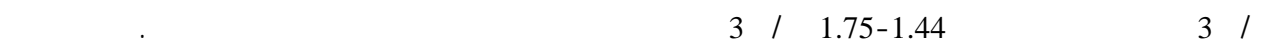

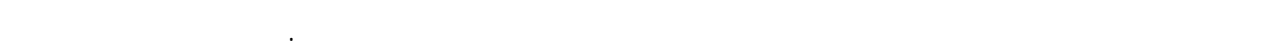

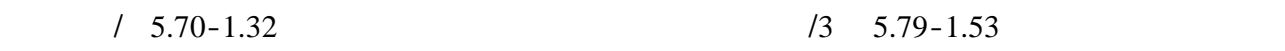

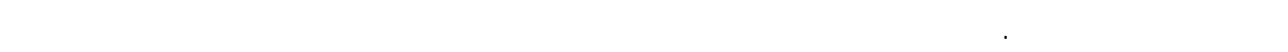

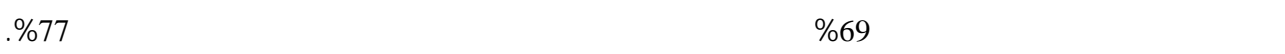

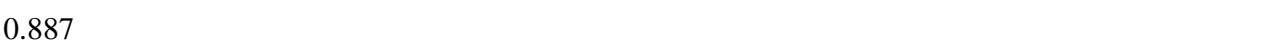

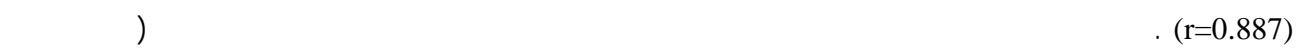

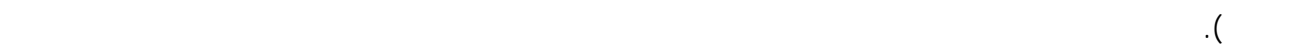

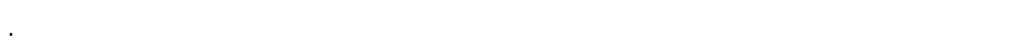

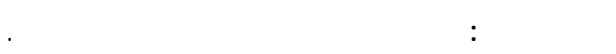

\section{Introduction}

Saudi Arabia is an arid country with a total land area of $2.253 \times 10^{6} \mathrm{~km}^{2}$. The majority of agricultural soils in Saudi Arabia are coarse textured and have low productivity due to poor water holding capacity, low organic matter content, initial low soil fertility, high infiltration rate and the presence of appreciable amounts of calcium carbonate and gypsum (Bashour et al.
1983).All these factors constitute a potential management problem of arid zone soils. Simultaneously, it is difficult to obtain a uniform application of water by surface irrigation resulting in poor irrigation efficiency. Some investigators have observed that machinery traffic and adoption of different tillage operations greatly influence the physical properties of coarse textured soils under different plant growth management systems (Douglas and McKyes, 
1978. Gaheen and Kjas, 1978. Akram and Kemper, 1979. Abo-Abda and Hussain, 1990). Researchers have stated that soil compaction with farm machinery decreased the hydraulic conductivity of the cultivated soils, the lowest values were found after one and four passes of the rubber-tracked tractor in the range of 1.5 and $0.08 \mathrm{~mm} \mathrm{hr}^{-1}$, respectively (Marsili et al. 1998, and Lowery and Schuler 1994). As such, owing to poor physical and chemical properties, the management of coarse textured soils in an arid environment is very difficult.

Tillage practices have great influence on soil physical conditions. This is due to the fact that after tillage, settling and trafficking of soil particles takes place resulting in rapid changes in the physical conditions of the soil until a new equilibrium is reached. The physical conditions of a soil can be measured to a greater extent by monitoring its bulk density, infiltration rate and hydraulic conductivity. Those in turn are related to pore size distribution and continuity. Increase in bulk density is correlated to an increase in resistance to penetration (Bauder et al. 1981), and a decrease in infiltration rate (Patel and Singh 1981). Crop production is dependant on a continuous process that conditions the soil through compaction caused by wheel traffic and alleviation of this compaction by tillage. Meek et al. (1988) reported that bulk density of a sandy loam soil can be reduced by tillage to a range of 1.4 to $1.5 \mathrm{Mg} \mathrm{m}^{-3}$. However, when a compaction force is applied by wheel traffic, bulk density and consequent soil compaction will increase to values that depends on factors such as soil moisture and wheel load (Soane et al. 1982). Bailey et al. (1993) stated that increased dynamic load at a constant tire inflation pressure caused increased soil stress and bulk density. Others researchers have demonstrated that wheel traffic significantly affected the soil compaction and soil physical properties (Voorhees et al. 1978; Lal et al. 1989). Meek et al (1992) carried out a study to evaluate important management practices as they relate to changes to in soil bulk density of a tilled sandy loam soil. They reported that a tire pressure of $408 \mathrm{kPa}$ along with a wheel mass of $2724 \mathrm{~kg}$ applied at moisture contents near field capacity resulted in a bulk density of $1.92 \mathrm{Mg} \mathrm{m}^{-}$ 3 , compared with a value of $1.67 \mathrm{Mg} \mathrm{m}^{-3}$ for no traffic. Harris (1971) reviewed the soil compaction processes and presented a stresscompaction relationship but stated that the possibility of rigorous relationship being established by analytical means is remote. Amir et al. (1976) presented an equation that made it possible to predict the amount of soil compaction as a function of contact pressure and soil moisture. Gupta et al. (1985) tested 85 soils and found that the Wasco sandy loam soil had the highest bulk density of any soil studied when compacted under standard conditions. Onstad et al. (1984) measured an increase in bulk density after tillage for four soils that correlated $\left(\mathrm{R}^{2}=\right.$ 0.84-0.96) to the amount of water applied. The time between tillage and the application of traffic may affect the final bulk density.

Utomo and Dexter (1981) measured the effect of uniaxial stress applied to aggregate beds that had been aged for 0-10 days. They found an increase in bulk density with increased aging. Lowery and Schuler (1994) showed that values of bulk density of soil increased with increasing level of compaction by 8 and 12 tons farm equipment. Mead et al.(1992) found that bulk density of the 0-75 $\mathrm{mm}$ soil layer increased from $1.55 \mathrm{t} \mathrm{m}^{-3}$ to $1.70 \mathrm{t} \mathrm{m}^{-3}$ when rolled with a rubber tire roller and decreased to $1.38 \mathrm{t} \mathrm{m}^{-3}$ when cultivated with a Cambridge cultipacker roller. Meek et al. (1992) found that tire pressure of $408 \mathrm{kPa}$ along with a wheel mass of $2724 \mathrm{~kg}$ applied at moisture contents near field capacity resulted in a bulk density of $1.92 \mathrm{t} \mathrm{m}^{-3}$ compared with a value of $1.67 \mathrm{t} \mathrm{m}^{-3}$ for no traffic. Stewart and Vyn (1994) stated that the differences in soil bulk density were significant from loading in all 3-tillage systems at the $5-10 \mathrm{~cm}$ depth interval. Gerik et al. (1987) observed on a silty clay soil that soil bulk density was greater from $0-2 \mathrm{~cm}$ deep for the wheel track of no till than for areas without wheel tracks of either no-till or chisel. Cassel et al. (1995) showed an increase in soil bulk density for tracked interrow areas of a controlled traffic study.

An extensive review of literature indicates that very little has been accomplished on soil 
compaction under the existing local soil, water and crop management conditions of Saudi Arabia. The main objective of this study was to determine the effect of tractor wheel compaction on bulk density and infiltration rate of coarse textured soil in Saudi Arabia and highlight the magnitude of its effect on water conservation for the improvement of irrigation efficiency in an arid environment.

\section{Materials and methods}

Study was carried out in a farmer field in the Eastern part Al-Ahsa Oasis during the production season of Alfalfa crop. The tested area extended over 0.6 ha. The farm cultivated alfalfa and citrus growing inbetween date palm trees. The field was previously cultivated with alfalfa for about six years. The soil consisted of 90 $\%$ sand, $4 \%$ Silt and $6 \%$ clay by weight with a soil textural class of loamy-sand. The soil was non-saline and non-sodic with a $\mathrm{pH}$ value of saturation paste as $7.88, \mathrm{EC}_{\mathrm{e}}$ of saturation paste extract as $2.01 \mathrm{dS} \mathrm{m}^{-1}$, Sodium Adsorption Ratio (SAR) of 2.10 , field capacity of $8.50 \%$ and a bulk density range of 1.44-1.55 g $\mathrm{cm}^{-3}$. The land was precisely leveled to $0.1 \%$ slope, irrigated and left for 2-3 days to attain a moisture level range of 6.5-8.0 $\%$ by weight basis. This allowed the soil moisture to range between field capacity (FC) and permanent wilting point (PWP) prior to the application of compaction treatments. Soil samples were taken from $0-15 \mathrm{~cm}$ depth at the time of treatment application for moisture determination gravimetrically. The main source of irrigation water was groundwater. The irrigation water was pumped from a well about $120 \mathrm{~m}$ deep with an EC of water as $2.65 \mathrm{dS} \mathrm{m}^{-1}$, a pH of 7.65 and SAR of 3.5.

The land was divide into two equal portions and was labeled as Site- 1 and Site-2. The land was irrigated according to the standard practice being followed at the farm for crop irrigation. and left for two days at site -1 to achieve the level of soil moisture to field capacity and for 3-days at Site-2 to reduce the moisture level slightly below the filed capacity level.

The experimental material consisted off one tractor (a Massey Ferguson Make), five tractor wheel passes treatments ranging from zero pass to 8-passes with an interval of 2-passes in between different treatments) and each treatment repeated three times. In all, there were 15-plots at each site.

The tractor (Massey Ferguson-Make, 2WD-47 PTO HP with a standard tire size of $46 \mathrm{~cm}$ and actual speed of $8 \mathrm{~km} \mathrm{hr}^{-1}$ ) was used to apply different compaction treatments. A total of five (5) soil compaction treatments were applied by repeatedly running the tractor over the experimental site. The five treatments were: control (zero-pass), low (2-passes), medium (4-passes), high (6-passes) and very high (8-passes of tractor) compaction according to the total number of tractor passes over the area. Zero compaction means that the soil was previously cultivated and not compacted by running over the tractor. The traffic application composed of a $2875 \mathrm{~kg}$ weight load and tire inflation pressure of $375 \mathrm{kPa}$ at a soil moisture close to field capacity $(7.95 \%)$.

The experiment was laid out by following A Randomized Complete Block Design. The soil compaction (repeated passes of tractor) was determined by a "Pocket Soil Penetrometer". The soil resistance was measured up to $15 \mathrm{~cm}$ depth of soil.

The size of each experimental plot was 10 x $5 \mathrm{~m}$ with a $2 \mathrm{~m}$ space in between two plots as buffer zone to avoid overlapping of additional soil compaction by tractor during treatment application. In order to apply different treatments, the tractor was run over the land as many times as the desired to complete the number of passes 
required for each treatment. The blocks within each site were the replicates according to the experimental design. The tractor was run with out any implement behind it. The soil infiltration rate and soil bulk density were measured from the piece of land runover by the tractor wheel to observe the impact of compaction on soil.

Soil bulk density was measured by taking three random undisturbed cores of soil from the piece of land runover by the tractor wheel from the experimental sites in sample cylinders. The edges of the sampling cores were trimmed and placed in moisture cans. The soil samples were oven-dried at $105^{\circ} \mathrm{C}$ to a constant weight. The volume of the core was determined from the dimensions of the sample cylinders. Soil bulk density was calculated by the procedure given by Bodman (1942).

The infiltration rate of soil was measured only at Site-1 by Double Ring Infiltrometer according to a method described by Aronovici (1955) and the measurements were repeated three times in the same area. Since the soil at both sites was similar in texture, hence the infiltration rate of soil was measured only on site No. 1. The infiltration rings were $45 \mathrm{~cm}$ long with a $30 \mathrm{~cm}$ inner diameter. The infiltration rings were inserted into the soil upto $25 \mathrm{~cm}$ depth as vertical as possible to make a tight bond between the cylinder and the soil. Buffer rings were placed outside the infiltration rings to eliminate the effect of lateral movement of water. The water used for the measurement of infiltration rate of soil was the same as that used to irrigate the field. A constant water head of $20 \mathrm{~cm}$ was maintained in each ring and the measurements were recorded at 5 minutes interval. The data were reported as mean values.

The experimental data were subjected to analysis of variance techniques according to Snedecor and Cochran (1973). A regression analysis was also run on soil data to determine correrelations between soil bulk density and infiltration rate of soil as well as between soil bulk density and cumulative infiltration rate of soil according to the procedure described by Snedecor and Cochran (1973).

\section{Results and discussion}

The bulk density of soil ranged between $1.55-1.79 \mathrm{~g} \mathrm{~cm}^{-3}$ at the first Site and 1.44$1.75 \mathrm{~g} \mathrm{~cm}^{-3}$ at the second site. The soil bulk density increased significantly with an increase in compaction by the number of passes by tractor wheel $\left[\left(\mathrm{LSD}_{0.05}=\right.\right.$ 0.029 and $\mathrm{R}^{2}=0.985$ for Site -1 ); $\mathrm{LSD}_{0.05}=0.039$ and $\mathrm{R}^{2}=0.979$ for Site-2). The difference in bulk density was statistically significant among all the treatments (Table $1 \&$ Fig.-1). The soil bulk density increased from $1.55 \mathrm{~g} \mathrm{~cm}^{-3}$ (control, no-compaction) to $1.79 \mathrm{~g} \mathrm{~cm}^{-3}$ (8-passes of tractor wheel) at site-1, whereas, it ranged between $1.444 \mathrm{~g} \mathrm{~cm}^{-3}$ (control, no compaction) to $1.75 \mathrm{~g} \mathrm{~cm}^{-3}$ (very high compaction treatment, 8-passes of tractor wheel) at site-2. This suggested that extensive running of wheel tractor caused significant changes in soil physical properties in the upper $0-15 \mathrm{~cm}$ depth of the tested soil. The soil bulk density change was shown at a soil moisture level close to field capacity of the experimental soil. The results agree with those of Meek et al. (1992) who reported an increase in soil bulk density from $1.67-1.92 \mathrm{t} \mathrm{m}^{-3}$ with a tire pressure of $408 \mathrm{kPa}$ and wheel weight of $2724 \mathrm{~kg}$ at moisture contents near field capacity. Similar results were also reported by Cassel et al. 1995 who found an increase in soil bulk density for tracked interrow areas of a controlled traffic area. Also Schuler (1994) showed that values of bulk density of soil increased with increasing level of compaction by 8 and 10 tons of farm machinery. 
Table 1. Effect of Compaction Treatment on Mean Bulk Density of Soil $\left(\mathrm{g} \mathrm{cm}^{-3}\right)$.

\begin{tabular}{lcccc}
\hline \multirow{2}{*}{ Compaction Treatment } & \multicolumn{2}{c}{ Site-1 } & Soil & \multicolumn{2}{c}{ Site-2 } & Soil \\
\cline { 2 - 5 } & \multicolumn{2}{c}{$(\mathbf{W C \%})$} & \multicolumn{2}{c}{ (WC\%) } \\
\hline 0-pass (control) & $1.55 \mathrm{e}$ & 7.07 & $1.44 \mathrm{e}$ & 5.29 \\
2-passes (low) & $1.60 \mathrm{~d}$ & 7.66 & $1.55 \mathrm{~d}$ & 5.15 \\
4-passes (medium) & $1.65 \mathrm{c}$ & 7.16 & $1.61 \mathrm{c}$ & 5.36 \\
6-passes (high) & $1.73 \mathrm{~b}$ & 7.10 & $1.66 \mathrm{~b}$ & 5.41 \\
8-passes (very high) & $1.79 \mathrm{a}$ & 6.99 & $1.75 \mathrm{a}$ & 5.25 \\
LSD $_{0.05}$ & 0.029 & & 0.039 & \\
\hline
\end{tabular}

Note: Figures followed by the same letter are not significantly different by $\mathrm{LSD}_{0.05}$. $\mathrm{WC}(\%)$ indicates soil moisture contents bv weight.

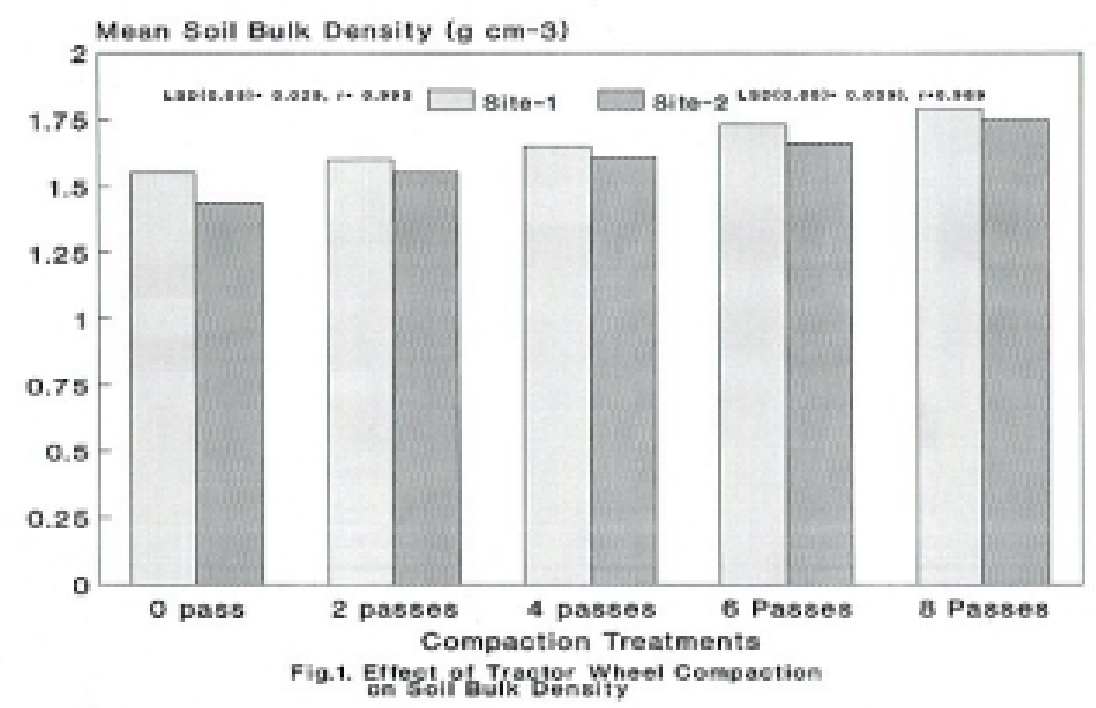

Wheel tractor compaction caused a significant reduction of cumulative water infiltration in soil. Mean values were 5.79, $4.37,2.13,1.73$ and $1.53 \mathrm{~cm}$ for control (zero compaction), low (2-passes), medium (4passes), high (6-passes) and very high (8passes) compaction treatments, respectively. The decrease in water infiltration in soil was higher in compaction treatments than the control treatment $\left(\mathrm{LSD}_{0.05}=0.271\right)$. The difference in cumulative water infiltration in soil was significant between low, medium and high compaction treatments but it was not significant between high and very high compaction treatments (Table 1 and Fig. 2). The reduction in cumulative water infiltration amounted up to $70 \%$ in high compaction treatment (6-passes of tractor wheel) than the control treatment (zero compaction). This suggested that application of high compaction treatment (6-passes) caused significant reduction in the cumulative infiltration rate of soils than the control treatment. The results agree with those of Abo-Abda and Hussain (1990) who reported significant reduction in cumulative infiltration rate of soil due to tractor wheel compaction of a sandy soil.

Water can be achieved if the soil compaction is possible with simple farm machinery such as tractor in sandy soils. This conclusion was drawn based on the fact that there was a significant reduction in 
water infiltration rate of soil after compaction. On the other hand, if the soil is not compacted then there will be a lot of deep percolation losses of applied irrigation water. The results agreed with the findings of Kemper et al. (1982), Elliott et al. (1983) and Abo-Abda and Hussain (1990) who found 20 to $40 \%$ reduction in infiltration rate of soil by tractor wheel compaction. The mean infiltration rate of soil decreased significantly with an increase in number of passes of tractor $\left(\mathrm{LSD}_{0.05}=0\right.$.). Mean values were $5.70,3.75,1.76,1.51$ and $1.32 \mathrm{~cm} \mathrm{hr}^{-1}$ for zero, low, medium, high and very high compaction treatments, respectively. The difference in the infiltration rates of soil was significant among zero, low and medium compaction treatments but it was not significant between medium and high as well as between high and very high compaction treatments (Table 2 and Fig. 2). The results indicate that more than $50 \%$ savings of applied

Table 2. effect of compaction treatments on mean water infiltration in soils $(\mathrm{cm})$.

\begin{tabular}{|c|c|c|}
\hline Compaction Treatment & $\begin{array}{c}\text { Cumulative } \\
(\mathrm{cm})\end{array}$ & $\begin{array}{c}\text { Infiltration Rate } \\
\left(\mathrm{cm} \mathrm{hr}^{-1}\right)\end{array}$ \\
\hline 0-pass (control) & 5.79 & 5.70 \\
\hline 2-passes (low) & $4.37(25)$ & $3.75(36)$ \\
\hline 4-passes (medium) & $2.13(63)$ & $1.76(69)$ \\
\hline 6-passes (high) & $1.73(70)$ & $1.51(74)$ \\
\hline 8-passes (very high) & $1.53(74)$ & $1.32(77)$ \\
\hline $\mathrm{LSD}_{0.05}$ & 0.271 & 0.261 \\
\hline
\end{tabular}

Note: Figures in brackets show the percent decrease in water infiltration from the control treatment (0-pass).

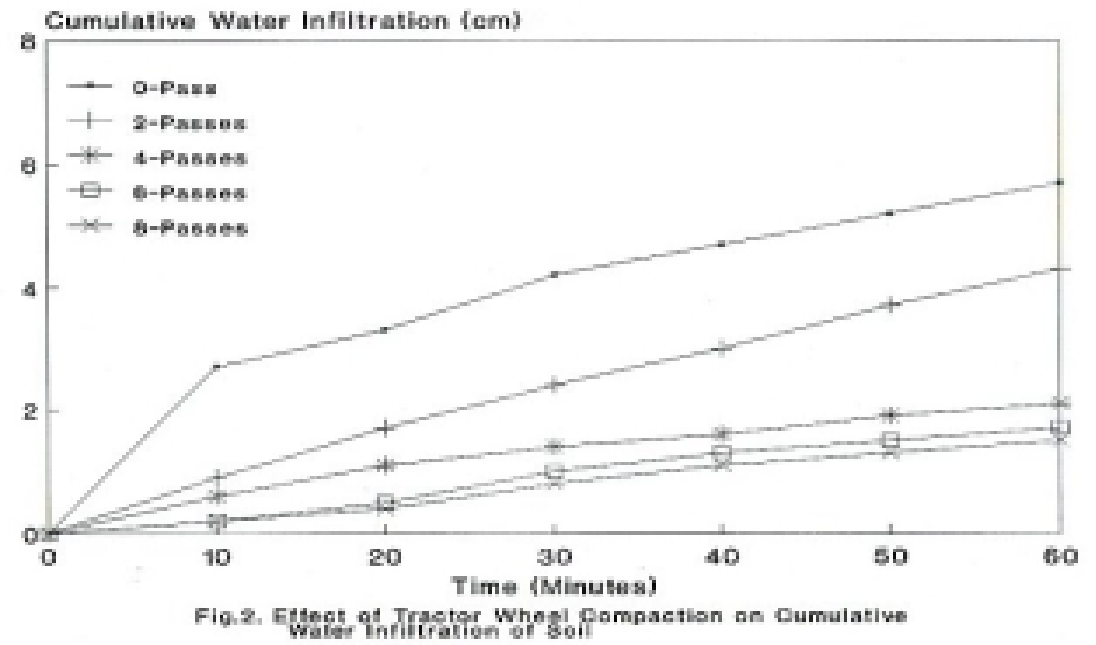


Relationship between Soil Bulk Density and Infiltration Rate of Soil

A regression analysis was run to determine the correlation between soil bulk density, infiltration rate and cumulative water infiltration of soil. It was observed that soil bulk density and infiltration rate of soil are highly correlated with correlation coefficient value of -0.887 and $\mathrm{R}^{2}$ (coefficient of determination) value of 0.985 (Fig.3). The $\mathrm{R}^{2}$ multiplied with 100 gives an overall percent relationship between the independent and the dependent variable. The
$\mathrm{R}^{2}$ value, as determined here, indicates that the infiltration rate of soil can be influenced up to $98.5 \%$ by the change in soil bulk density. This would mean that infiltration rate of soil can be reduced significantly by increasing the soil bulk density by tractor wheel compaction or another farm equipment.

A similar analysis was run between soil bulk density and mean cumulative water infiltration of soil (Fig.4). The value of correlation coefficient (r) came to 0.91 with $\mathrm{R}^{2}$ value of 0.996 .
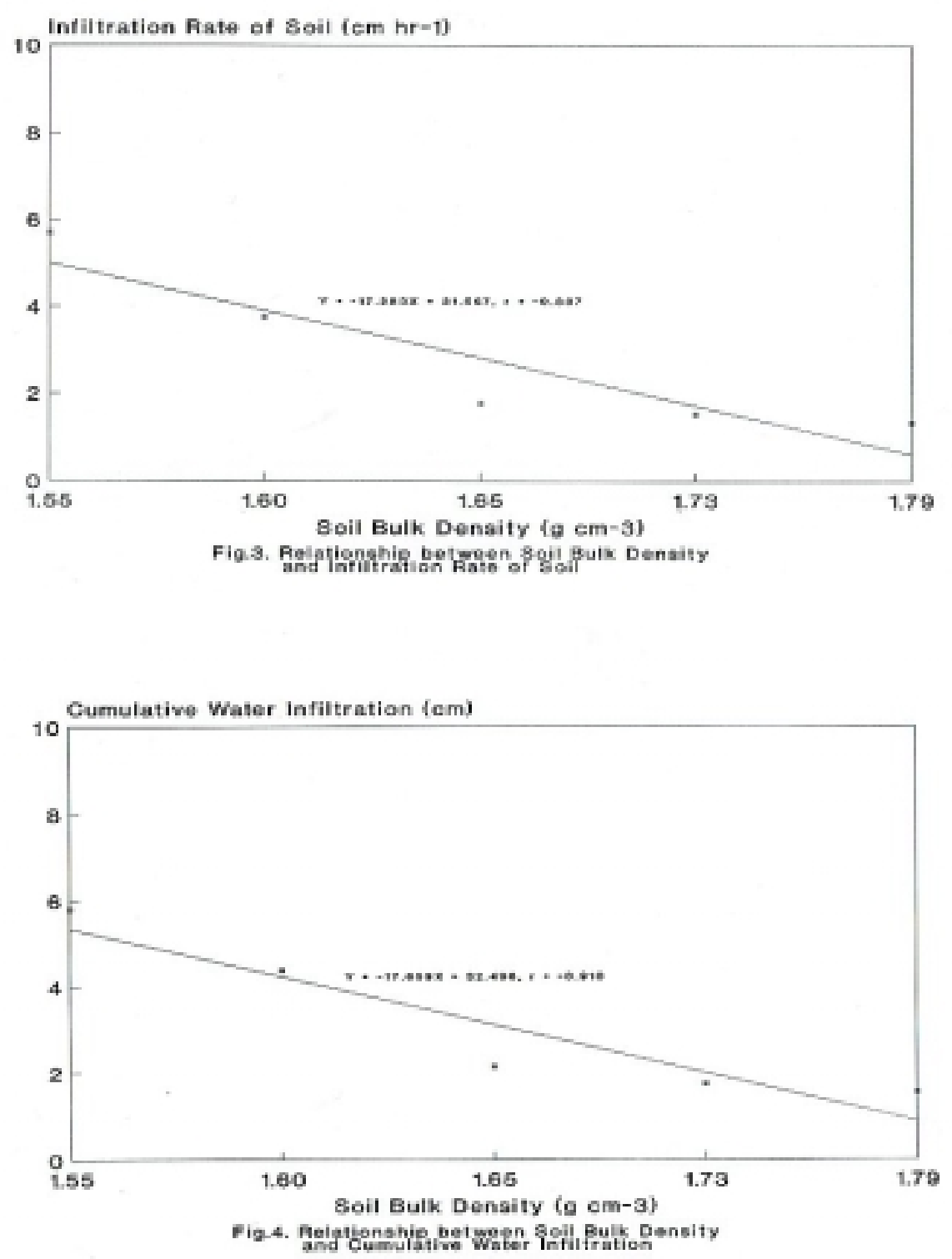


\section{Conclusions}

Soil bulk density increased significantly from $1.55-1.79 \mathrm{~g} \mathrm{~cm}^{-3}$ at site- 1 and $1.44-$ $1.75 \mathrm{~g} \mathrm{~cm}^{-3}$ at site- 2 with an increase in soil compaction by increasing the number of passes of tractor wheel when the soil moisture was near field capacity. Cumulative water infiltration and Infiltration rate of soil were reduced significantly with tractor wheel compaction. Also, irrigation application losses through deep percolation could be reduced up to $70 \%$ by compacting coarse textured soils with tractor wheel. The correlation between soil bulk density and the infiltration rate of soil was very high ( $\mathrm{r}$ $=0.989$ ). This inferred that soil infiltration rate could be reduced significantly with tractor wheel compaction thus resulting in higher water use efficiencies. Soil compaction with tractor wheel appears to be a potential tool for changing the soil physical properties (such as bulk density, infiltration rate, water holding capacity) to conserve more water for the development of coarse textured soils in an arid environment.

The change in soil bulk density can significantly influence the infiltration rate of soil thus improving soil water holding capacity. Results of the study suggest that the infiltration rate of soils can be suppressed by tractor wheel compaction over a land under cultivation for productivity improvement and reduction of irrigation water losses which occur due to high percolation rate of coarse textured soils.

Further studies are required to test and evaluate a variety of agricultural equipments currently used in the Kingdom of Saudi Arabia to determine the effect of its respective compaction on soil physical properties for water conservation.

\section{References}

Abo-Abda, A. E., and G. Hussain. 1990. Impact of machinery compaction and tillage systems on infiltration rate of sandy soils. Arid Soil Res. Rehabilitation 4:157-162.

Akram, M., and W. D. Kemper. 1979. Infiltration of soils as affected by the pressure and water content at the time of compaction. Soil Sci. Soc. Am. J. 43:1080-1086.

Amir, I., G. S. V. Raghvan, E. McKyes, and R. S. Broughton. 1976. Soil compaction as a function of contact pressure and soil moisture content. Can. Agric. Eng. 18:54-57.

Aronovici, V. S. 1955. Model study of ring infiltrometer performance under low initial soil moisture. Soil Sci.

Soc.Am. Proc. 18:1-6.

Bailey, A. C., R. L. Raper, T. R. Way, E. C. Burt, and C. E. Johnson. 1993. Soil stress under tractor tires at various inflation pressures. Proceedings of 11th International Conference of the ISTVS, 1:276- 285. Lake Tahore, NV. USA. September 27-30.

Bashour, I. I., A. S. Al-Mashhady, D. Prasad, J. Miller, and M. Mazroa. 1983. Morphology and composition of some soils under cultivation in Saudi Arabia. Geoderma 29:327-340.

Bauder, J. W., G. W. Randall, and J. B. Swan. 1981. Effect of four continuous tillage systems on mechanical impedance of a clay loam soil. Soil Sci. Soc. Am. J. 45:802-806.

Bodman, G. B. 1942. Nomograms for rapid calculation of soil density, water content and total porosity relationship. J. Am. Soc. Agron. 34:883-893.

Cassel, D.K., C.W. Razkowski, and H.P. Denton. 1995. Tillage effects on corn production and soil physical 
conditions. Soil Sci. Soc. Am. J. 59:14361443.

Douglas, E., and E. McKyes. 1978. Compaction effect on the hydraulic conductivity of a clay soil.

Soil Sci. 125:278-282. 1liott, R. L., W. R. Walker, and C. V. Skogerboe. 1983. Infiltration parameters from furrow irrigation advance data. Trans. ASAE 26(6):1726-1731.

Gaheen, S. A., and A. Kjas. 1978. Long term effects of tractor and lining on surface elevation changes, infiltration rate and surface cracking of a silty clay loam soil. As. Norway Agricultural University, Department of Soil and Fertility Management, Report No. 87-b. As, Norway.

Gerik, T.J., J.E. Morrison, jr., and F.W. Chichester. 1987. Effects of controlled traffic on soil physical properties and crop rooting. Agron. J. 79:434-439.

Gupta, S. C., A. Hadas, W.B. Voorhees, W. Wo;f, W.E. Larson, and E.C.Schneider. 1985. Development of guides for estimating the ease of compaction of world soils. Univ. of Minnesota, St. Paul, MN-USA.

Harris, W. L. 1971. The soil compaction process. p. 9-44: In K.K. Barnes et.al. (ed.) Compaction of Agricultural soils. ASAE Monog. 1. ASAE, st. Joseph, MI-USA.

Kemper, W. D., B. J. Ruffing, and J. A. Bondurant. 1982. Furrow intake rates and water management. ASAE 25(2):333-339.

Lal, R., T. J. Logan, N. R. Fausey, and D. J. Eckert. 1989. Long term tillage and wheel traffic effects on a poorly drained Mollic Ochraqualf in northwest Ohio: Soil physical properties, root distribution and grain yield of corn and soya bean. Soil and Tillage Res. 14:341-358.

Lowery, B., and R. T. Schuler. 1994. Duration and effects of compaction on soil and plant growth in Wisconsin. Soil and Tillage Res. 29(2-3):205-210.

Marsili, A., P. Servadio, M. Oagliai, and N. Vignozzi. 1998. Changes of some physical properties of a clay

soil following passage of rubber and metal-tracked tractors. Soil and Tillage Res. 49(3):185-199.

Mead, J. A., A. L. Palmer, and K. Y. Chan. 1992. Effect of seedbed conditions on sowing point performance. Soil and Tillage Res. 22(1-2):13-25.

Meek, B. D., E. R. Rechel, L. M. Carter, and W. R. DeTar. 1988. Soil compaction and its effect on alfalfa in zone production systems. Soil Sci. . A. J. 51:-236.

Meek, B. D., E. R. Rechel, L. M. Carter, and W. R. DeTar. 1992. Bulk density of a sandy loam: Traffic, tillage, and irrigation-method Effects. Soil Sci. Soc. Am. J. 56:562-565.

Onstad, C.A., M.L. Wolfe, C.L. Larson, and D.C. Slack. 1984. Tilled soil subsidence during repeated wetting. Trans. ASAE 27:733-736.

Patel, M.S., and N.T. Singh. 1981. Changes in bulk density and water intake rate of coarse textural soil in relation to different levels of compaction. J. Ind. Soc. Soil Sci. 29:110-112. 
Snedecor, G. W., and W. G. Cochran. 1973. Statistical Methods, 6th ed. Iowa State University, Ames, Iowa. USA.

Soane, B.D., J.W. Jackson, and D.J. Campbell. 1982. Compaction of agricultural vehicles-A review III. Incedence and control of compaction in crop production. Soil Tillage Res.2:3-36.
Stewart, G. A., and T. J. Vyn. 1994. The influence of high axle loads and tillage systems on soil properties and grain corn yield. Soil and Tillage Res. 29(23):229-235.

Voorhees, W. B., G. C. Senst, and W. Nelson. 1978. Compaction and soil structure modification by wheel traffic in the northern Corn belt. Soil Sci. Soc. Am. J. 42:344-349. 